\title{
PARCERIA UNIVERSIDADE-PREFEITURA: UM ESTUDO DO TRÁFEGO DE VEÍCULOS EM JUIZ DE FORA
}

Caio M. Castro1; Fernando A. Carvalho1; Marcelo M. Barros²; Matheus P. Silva'; Renan C. Pinto'.

'Discentes do curso de Engenharia Civil UFJF e Bolsistas do PET/SESU/MEC; ${ }^{2}$ Docente do curso de Engenharia Civil/Tutor do PET Civil UFJF.

PET Civil UFJF, Universidade Federal de Juiz de Fora, Juiz de Fora, Minas Gerais.

Palavras-chave: Tríade Ensino-Pesquisa-Extensão; Análise de dados; Trânsito; Inovação.

\section{Introdução}

Dada a importância de parcerias entre Universidades e Órgãos Públicos, o PET-Civil-UFJF estabeleceu uma parceria com a Secretaria de Transportes e Trânsito (SETTRA) de Juiz de Fora para o desenvolvimento de projetos a fim de melhorar o trânsito da cidade, considerada de médio porte. A proposta consiste em envolver também os PETs Elétrica e Computacional num trabalho multidisciplinar envolvendo Ensino, Pesquisa e Extensão. Neste projeto pretende-se desenvolver: uma comunicação efetiva entre os semáforos da cidade e a central de monitoramento; um software para realizar contagem e identificação de veículos através das imagens das câmeras presentes em cruzamentos da cidade; uma análise de Big Data dos dados de tráfego, ônibus, táxis e estacionamentos na cidade.

\section{Metodologia}

Neste primeiro momento estão sendo analisados dados de volume de tráfego em pontos da cidade que possuem radares, pois os radares fornecem estes dados. Assim, foram contabilizados os volumes ao longo dos dias, das 
semanas e dos meses em termos de média e intervalo de confiança. A partir dos dados foram gerados gráficos para auxiliar na interpretação do comportamento do volume de tráfego. Em resumo, a metodologia utilizada para o desenvolvimento do projeto pode ser organizada na seguinte ordem:

1) Tomada dos dados crus (volumes por hora) com a SETTRA;

2) Organização e tratamento estatístico dos dados;

3) Geração dos gráficos correspondentes aos volumes médios e desvios;

4) Estudo dos padrões presentes nos gráficos;

5) Interpretação dos padrões presentes nos gráficos;

6) Conclusões.

O Intervalo de Confiança (IC), dentro da Estatística, fornece uma medida de variabilidade dos dados. Neste trabalho, considerou-se o valor de 2,5\% de margem de erro tanto para mais (em amarelo), quanto para menos (em vermelho). Desta forma, existe uma probabilidade de $95 \%$ dos dados estarem dentro do intervalo de confiança.

\section{Resultados e discussão}

Um conjunto de dados de volume de tráfego que está sendo analisado corresponde a uma das entradas/saídas da cidade, no km 799 da BR-040, denominada Avenida Deusdedith Salgado, conforme Figura 1 (direita). Os dados do volume de saída de veículos são captados no número $3600 \mathrm{C} / \mathrm{B}$ (Centro/Bairro) com os radares 118 e 119. Os dados de volume de entrada de veículos são captados no número 4895 B/C (Bairro/Centro) com os radares 116 e 177.

O outro conjunto de dados corresponde à principal avenida da cidade, Avenida Barão do Rio Branco, onde serão analisados três pontos ao longo dela, conforme Figura 1 (esquerda). Dois equipamentos da avenida possuem sentido Bairro/Centro (B/C): no número 4395 (radares 039 e 040) - fluxo de origem da zona sul e no número 190 (radares 035 e 036) - fluxo de origem da zona norte. Além disso, a via possui o equipamento localizado no número 229 , sentido Centro/Bairro (C/B), correspondendo ao radar 136. 
Figura 1: Avenida Barão do Rio Branco (esquerda), Avenida Deusdedith Salgado (direita) e a distribuição dos radares.
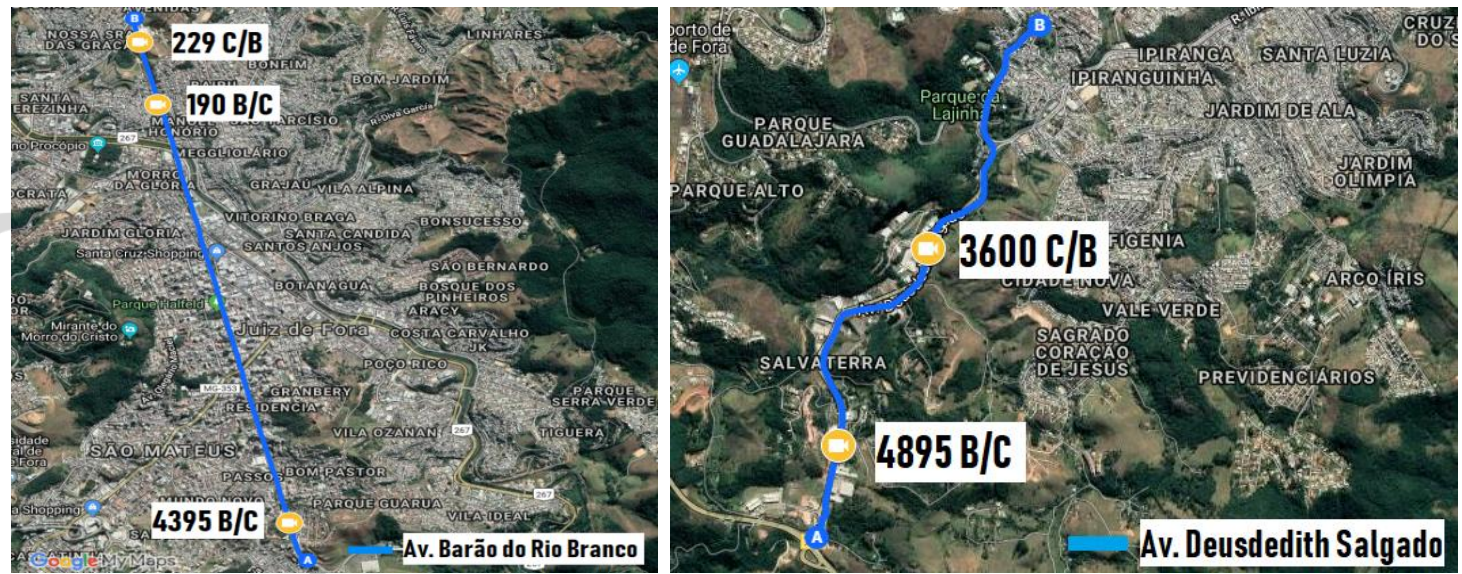

Fonte: Adaptado de Google Maps, 2019.

\section{Análise dos radares da Avenida Barão do Rio Branco:}

A partir da Figura 2 observou-se uma similaridade considerável entre os gráficos dos radares 229 e 4395 da Av. Barão do Rio Branco, já o radar 190 se destoa em relação aos anteriores. O radar 190 possui um maior volume de veículos se comparado com os demais na mesma via.

Figura 2: Gráfico de volume ao longo das horas do dia dos radares 4395 B/C (esquerda), 229 C/B (direita) e 190 B/C (baixo) da Av. Barão do Rio Branco.
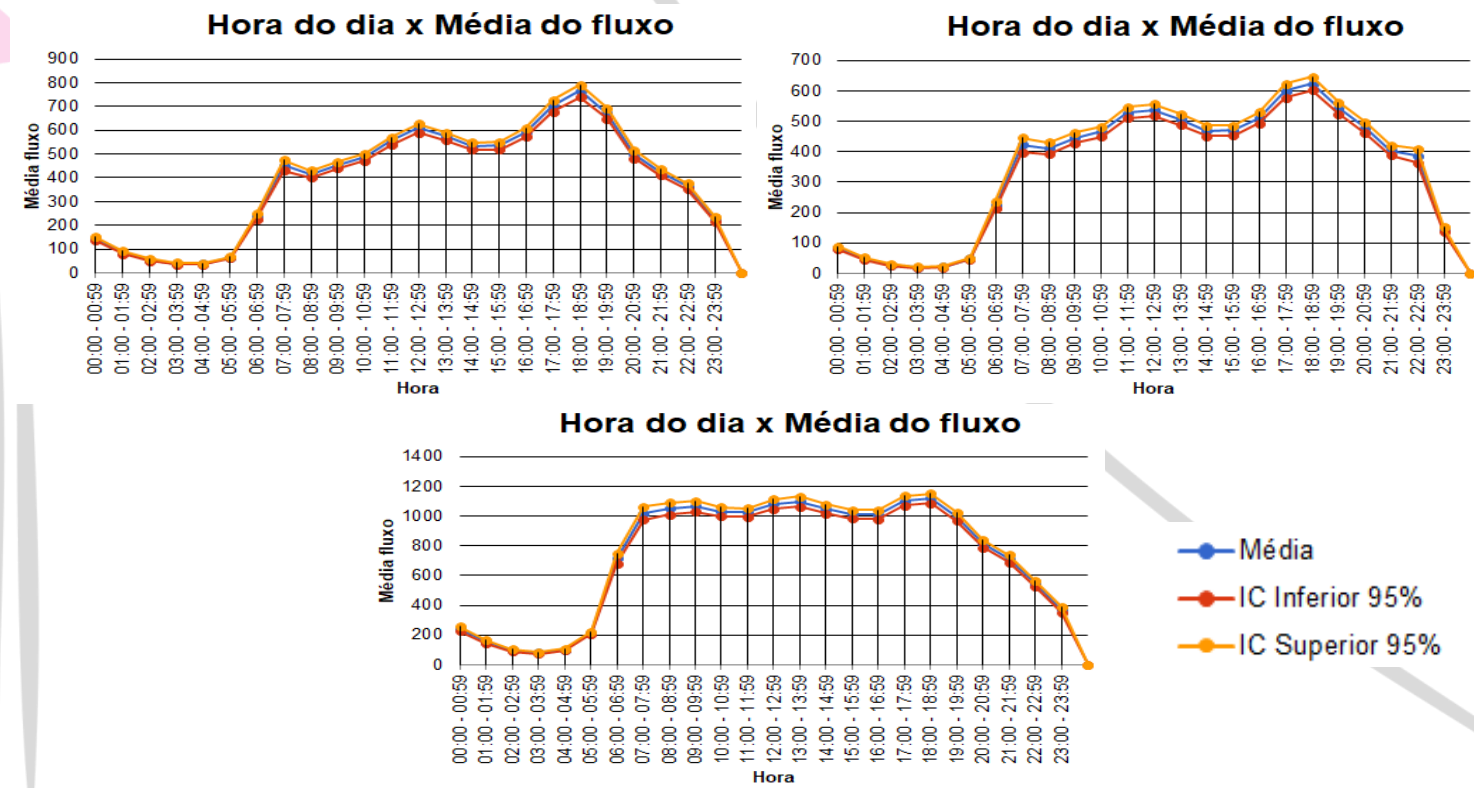
Em relação aos meses do ano (Figura 3) os radares 229 e 4395 possuem um pico máximo do fluxo de veículos em Agosto.

O radar 4395 possui uma baixa considerável no volume do tráfego nos meses de Maio, Junho e Julho. Os motivos dessa queda ainda são desconhecidos.

Figura 3: Gráfico de volume ao longo dos meses para os radares 4395 B/C (esquerda) e 229 C/B (direita) da Av. Barão do Rio Branco.

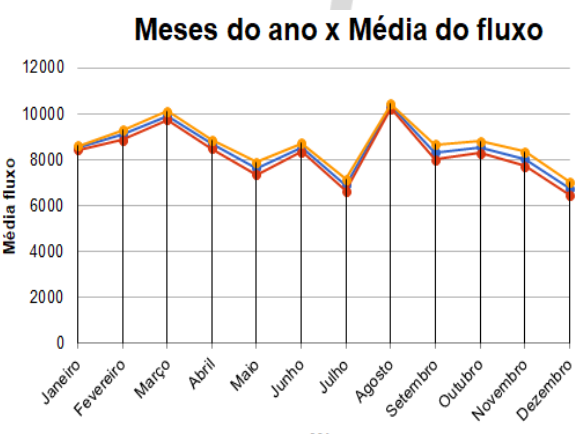

Mês

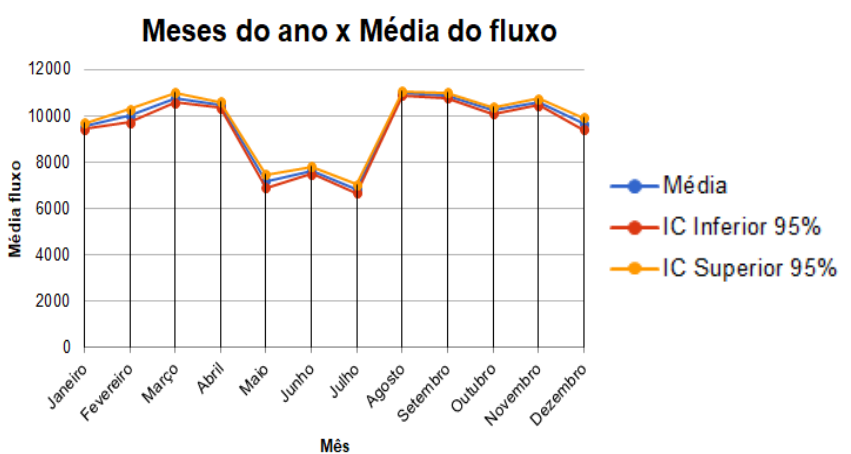

Mês

Fonte: Os autores, 2018.

\section{Análise dos radares na Avenida Deusdedith Salgado:}

$\mathrm{Na} \mathrm{Av}$. Deusdedith Salgado possui um radar orientação B/C número 4895 (radares 116 e 117) e o outro no sentido C/B número 3600 (radares 118 e 119). O que se percebe através da curva "Hora do dia x Média do fluxo" (Figura 4) dos radares é que durante o período da manhã, saem mais veículos da cidade do que adentram na mesma. Isso se inverte durante a tarde, no horário entre $16 \mathrm{~h}$ e 20h, no qual chegam veículos na cidade do que saem, sugerindo a existência de um movimento pendular.

Figura 4: Gráfico de volume ao longo das horas dos dias para os radares $4895 \mathrm{~B} / \mathrm{C}$ (esquerda) e 3600 C/B (direita) da Av. Deusdedith Salgado.
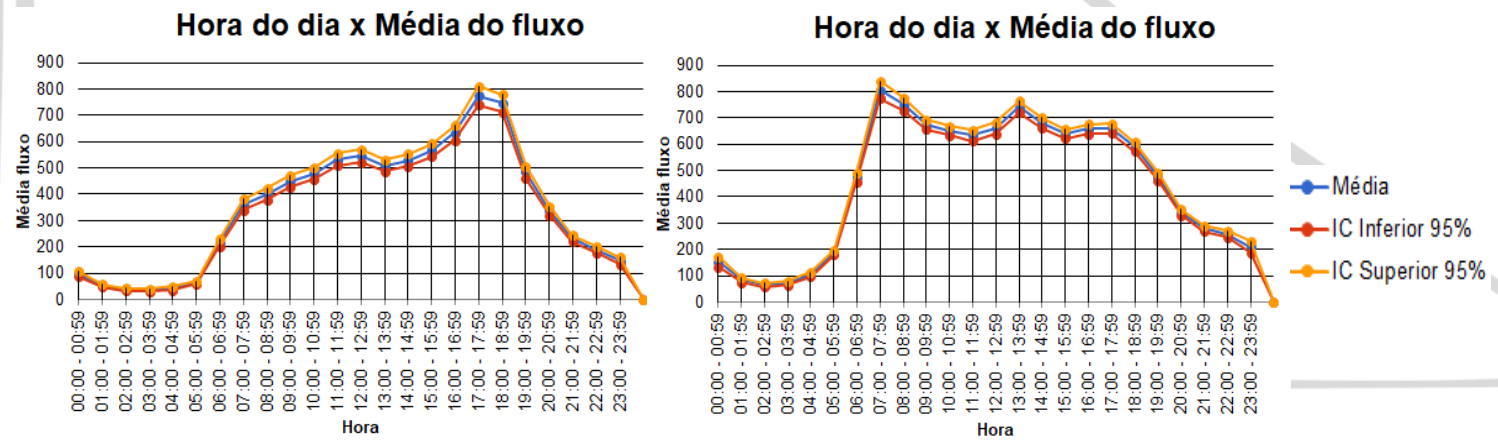

Fonte: Os autores, 2018. 
Analisando o fluxo nessa via ao longo dos meses, não foi possível observar similaridade entre os gráficos dos dois radares (Figura 5), o radar 3600 no sentido $\mathrm{C} / \mathrm{B}$ possui um comportamento mais linear com picos máximo em Abril e Agosto, já o radar 4895 no sentido B/C possui alta variação em seu fluxo, com picos máximos em Janeiro e Dezembro, correspondendo com o período de férias escolares.

Figura 5: Gráfico de volume ao longo dos meses para os radares $4895 \mathrm{~B} / \mathrm{C}$ (esquerda) e 3600 C/B (direita) da Av. Deusdedith Salgado.
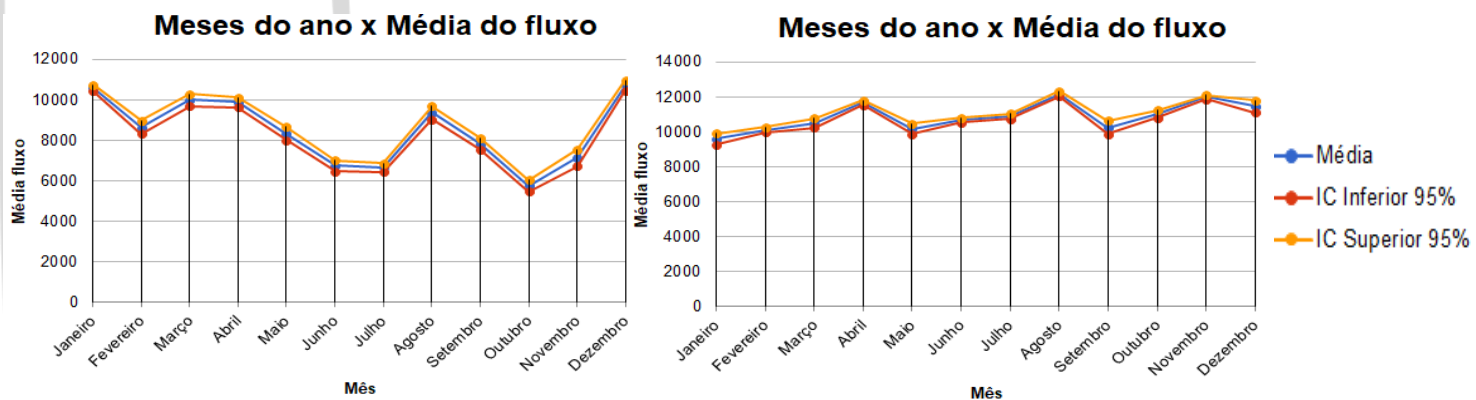

Fonte: Os autores, 2018.

\section{Similaridade nos volumes ao longo dos dias da semana}

Os volumes ao longo dos dias da semana apresentaram mesmo aspecto para todos os radares (Figura 6), os três da Av. Barão do Rio Branco e os dois da Av. Deusdedith Salgado. Embora haja diferença nas quantidades entre eles, em todos eles os volumes aumentam de forma, aproximadamente, lineares desde segunda-feira até sexta-feira. No sábado o volume se reduz um pouco e no domingo se reduz muito, voltando a aumentar na segunda-feira seguinte.

Figura 6: Gráfico de volume ao longo dos dias da semana para os radares: Av. Barão do Rio Branco 190 B/C (esquerda) e Av. Deusdedith Salgado 3600 C/B (direita).
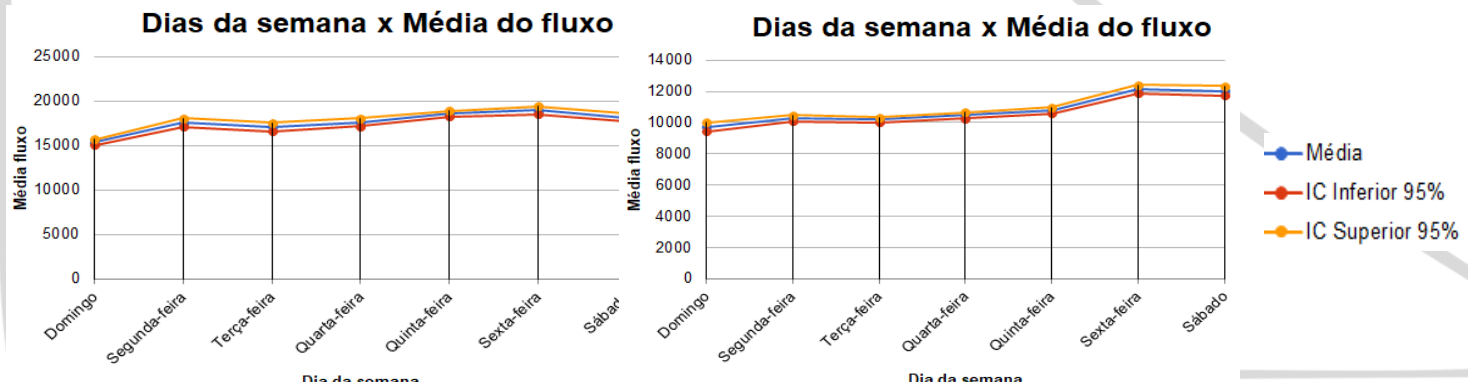

Fonte: Os autores, 2018. 


\section{Conclusões}

A princípio esperava-se que, pelo fato de Juiz de Fora ser uma cidade de porte médio, houvesse maior entrada de veículos na cidade durante o dia e saída ao final do dia, de pessoas indo trabalhar/estudar. Porém, o que os dados dos radares, localizados na entrada da cidade no km 799 da BR-040, mostram é que há um maior volume de saída de pessoas da cidade pela manhã e retornando ao final da tarde. Portanto, a partir do estudo que está sendo desenvolvido pelo PET-Civil pretende-se auxiliar a Prefeitura na tomada de decisões a partir de uma maior compreensão da dinâmica dos veículos que circulam na cidade de Juiz de Fora.

Este projeto está ainda em fase inicial e, juntamente com os PETs Elétrica e Computacional, espera-se contribuir para a inovação e otimização do trânsito na cidade de Juiz de Fora com os projetos de comunicação entre semáforos e contagem de veículos por imagens de câmeras, respectivamente.

\section{Referências}

BUSSAB, W. O.; MORETTIN, P. A. Estatística Básica: 9. ed. São Paulo: Saraiva, 2017.

Dados fornecidos pelo Centro de Controle e Monitoramento da Secretaria de Transportes e Trânsito (CCM/SETTRA) de Juiz de Fora, 2018, acesso restrito. 